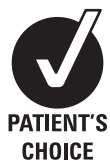

CHOICE
${ }^{1}$ Neuromuscular Clinic, Department of Neurology, University Hospitals of Leicester, Leicester, UK ${ }^{2}$ Department of Neuroscience and Imaging, University "G. d'Annuzio", Chieti-Pescara, Italy

Correspondence to Dr Yusuf A Rajabally, Neuromuscular Clinic, Department of Neurology, University Hospitals of Leicester, Leicester General Hospital, Leicester LE5 4PW, UK;

yusuf.rajabally@uhl-tr.nhs.uk

Received 30 November 2011 Revised 30 March 2012 Accepted 4 April 2012 Published Online First 7 May 2012

\title{
Outcome and its predictors in Guillain-Barré syndrome
}

\author{
Yusuf A Rajabally, Antonino Uncini ${ }^{2}$
}

\begin{abstract}
Despite the use of plasma exchanges and intravenous immunoglobulins, Guillain-Barré syndrome (GBS) still carries non-negligible morbidity and mortality. Furthermore, the psychosocial consequences of GBS may persist longer than expected. Various aetiological, clinical, electrophysiological and immunological factors may carry prognostic predictive value. The objective of this article was to perform a summary of the current knowledge-base on outcome and its determinants in adequately-treated adult-onset GBS. Relevant prospective literature was reviewed through a Medline search of English-language articles published between 1966 and March 2012. GBS causes severe persistent disability in $14 \%$ of patients at 1 year. Loss of full strength, persistent pain and need for professional change occurs in about $40 \%$. Mortality is of about $4 \%$ within the first year. Analysis of prognostic predictors consistently demonstrates the negative impact of higher age, preceding diarrhoea, greater disability/weaker muscles at admission, short interval between symptomonset and admission, mechanical ventilation and absent/ low amplitude compound muscle action potentials. Further outcome studies will soon be underway and may in future contribute to adequately integrate all potential factors in more reliable predictive models.
\end{abstract}

\section{INTRODUCTION}

Guillain-Barré syndrome (GBS) is an acute, usually postinfectious neuropathy of common occurrence with a yearly incidence rate between 1.1 and 1.8 per $100000 .{ }^{1}$ More recent data from a meta-analysis of 13 epidemiological studies from Europe and North America refined the estimated yearly crude incidence as lying between 0.81 and 1.89 per $100000 .^{2}$ GBS incidence increases exponentially with age, with age-specific rates increasing from 0.62 per 100000 among 0-9-year-olds to 2.66 per 100000 among 80-89-year-olds. Male subjects are more commonly affected with an RR of $1.78 .^{2}$ The most common preceding infection causing GBS has been shown to be Campylobacter jejuni enteritis. Other incriminated infectious agents include cytomegalovirus, Epstein-Barr virus, Mycoplasma pneumoniae and Haemophilus influenzae. ${ }^{3}$ In its typical form, GBS causes rapidly progressive diffuse proximal and distal weakness of the four limbs, sensory loss and symptoms and areflexia. By definition, the maximal weakness is reached within 4 weeks. However, in the majority of cases, nadir is attained within 2 weeks. Facial, bulbar and respiratory muscle weakness is frequent, and autonomic involvement well described. The diagnosis of GBS is clinical but may be aided by electrophysiology which is also important to characterise the two main electrophysiological subtypes: acute inflammatory demyelinating polyradiculoneuropathy (AIDP), which is sensory and motor and displays demyelinating changes on nerve conduction studies, and acute motor axonal neuropathy (AMAN), which is primarily axonal and thought to be purely motor. There are also axonal forms with sensory involvement described as acute motor and sensory axonal neuropathy (AMSAN). More recently, it has been shown that the pathophysiology of axonal subtypes is characterised besides axonal degeneration by reversible conduction failure and that AMAN and AMSAN which share a common immunological profile and electrophysiological features represent a continuum in the axonal GBS spectrum. $^{4} 5$ Rise in cerebrospinal fluid (CSF) protein level with normal CSF cellularity, also known as 'albumino-cytological dissociation', is characteristic of GBS, and present in over $90 \%$ of patients 2 weeks postonset. ${ }^{2}$ Imaging can also be contributory to the diagnosis of GBS, with MR of the lumbar spine demonstrating thickened and/or enhancing nerve roots. ${ }^{6}$

The prognosis of GBS is generally considered favourable. Despite the demonstrated efficacy of plasma exchange (PE) and intravenous immunoglobulins (IVIg), GBS however remains a disabling disease in a significant proportion of patients, and these treatments have not improved mortality. Long-term function is compromised in a significant proportion of subjects. Prognosis and potential determinants of clinical outcome in the disorder have been studied by several investigators in more recent years. Although several review articles have considered the various aspects of GBS, a synthesis of the important question of prognosis and its determinants has not, to date, to our knowledge, been performed. In this article, we review the literature on the specific issue of outcome and its predictors in adequately treated, adult-onset GBS.

\section{METHODS}

The literature between 1966 and March 2012, searched from Medline, on outcome and its predictors in PE or IVIg treated adult-onset GBS was reviewed. The search terms 'Guillain-Barré syndrome', 'treatment', 'prognosis', 'predictors' and 'outcome' were utilised. Only papers published in English were considered. From the papers found from an initial search, we exclusively reviewed and here report for the outcome study those relating to prospectively conducted studies on prognosis in 
GBS patients of adult age, adequately treated by PE or IVIg, currently the only two evidence-based treatments for GBS, established at two (for mild cases) or four (for moderate or severe cases) sessions of PE, or alternatively, IVIg at the dose of $2 \mathrm{~g} / \mathrm{kg}$, over 2 or 5 days. 78

The outcome measures used varied in different studies and time to improve on the GBS disability scale was the main prognostic data available. However, as in clinical practice questions of importance relate to probabilities for a given patient to reach particular levels of function at specific times, we considered predetermined outcome measures rather than median times taken to reach one particular stage, especially given the wide standard deviations. The main outcome measures that we decided to derive from the literature were the probabilities, following adequate treatment, of:

1. Ability to walk with aid at 4 weeks

2. Ability to walk unaided at 4 weeks

3. Need for ventilatory support at 4 weeks

4. Ability to walk without aid at 6 months

5. Occurrence of a relapse within 1 year

6. Recovery of full motor strength recovery at 1 year

7. Ability to walk without aid at 1 year or later

8. Persistence of severe motor sequelae (defined by the loss of at least one of the following six functions: ability to walk, with or without aid, climb stairs, dress, cut meat, or write) at 1 year

9. Need to change professional activity due to GBS by 1 year

10. Death within the first year.

Finally, the literature referring to prospective studies about potential prognostic predictors in treated GBS was reviewed and analysed considering prospective studies where a majority, but not necessarily all patients, were adequately treated.

\section{RESULTS}

Outcome in appropriately treated GBS: analysis of prospective studies

Initial literature on GBS prognosis relates to retrospective studies done prior to use of PE and IVIg and states recovery rates of $50 \%-94 \%$. 910

We initially considered a total of 29 papers relating to prospective literature on the topic. We excluded 19 studies where not all patients had been appropriately treated. In the following sections, we summarise the data on preselected outcome measures of the 10 included studies. As PE and IVIg are now considered equally effective treatments in GBS, outcome data were pooled.

The first placebo-controlled trial of PE for GBS was published in $1984 .{ }^{11}$ Although the results were negative, the prognostic data for the treated group is here used for recovery of full strength at 1 year, mortality, severe motor sequelae at 1 year and relapses within the first year. A second study randomised 38 GBS patients to receive PE or supportive care alone. ${ }^{12}$ Although also negative for its primary outcome measure, this trial provided data for most of our prognostic questions for treated patients. The North-American plasma exchange study provided data on several measures within the first year. ${ }^{13} 14$ The French Cooperative Group on Plasma Exchange published in 1987 and complemented in 1992 with 1-year data gave information for most selected prognostic questions. ${ }^{15}{ }^{16}$ A further PE trial was published in $1987,{ }^{17}$ and provided us with 1-year data on recovery of full motor strength, mortality, presence of severe motor sequelae and relapses. A randomised controlled trial of the Dutch Guillain-Barré Study Group comparing IVIg and PE followed in $1992{ }^{18}$ From Kaplan-Meier curves shown, only
$10 \%-20 \%$ of patients from both groups recovered independent locomotion at 4 weeks. More precise data were not available. Mortality data at 1 year were used in our final analysis.

In 1997, the second French trial of PE was published. ${ }^{19}$ Patients were stratified into severity groups: 'mild' (who were able to walk with or without help but who could not run, or who could stand up unaided), 'moderate' (who could not stand up unaided) and 'severely affected' (requiring mechanical ventilation) and randomised to have different number of PE sessions or no treatment. Two sessions of PE for the mild group and four for the moderate and severe groups were shown to be effective. The results of the study provide data on 1-year functional outcome for the three groups. We used these data, considering, for each outcome measure, the patient groups receiving the number of PE sessions found effective versus supportive care only or versus another number of PEs.

A comparative trial of PE versus IVIg versus PE followed by IVIg was later published in $1997 .{ }^{20}$ One of the secondary outcome measures was the ability or not to walk unaided at 48 weeks. Relapse and mortality data up to 48 weeks were also provided. We considered 48-week data not to be likely significantly different from 1 year and included them in our analysis. As the three treated groups (PE, IVIg and PE+IVIg) did not differ in outcome, we used mean proportions of the three groups.

In 2004, the Dutch study of methylprednisolone in addition to IVIg versus IVIg alone in GBS was reported. ${ }^{21}$ One secondary outcome measure of use in our analysis was the proportion of patients able to walk independently at 1 year. This, comparable in between treated groups, averaged $81.8 \%$. Mortality data at 1 year were also included.

The first long-term study of residual health status was published in 1997 analysing a cohort of 123 GBS patients followed up 3-6 years after their illness. ${ }^{22}$ All had participated in the Dutch IVIg versus PE trial. ${ }^{18}$ The authors found residual altered psychosocial function in all GBS patient groups whether or not they had persistent residual symptoms. However, the 'physical sickness impact profile' score correlated with the GBS functional score. The same group later showed long-term reduction in health-related quality of life despite good physical recovery ${ }^{23}$ and studied the effects on private life of GBS patients 3-6 years after the illness, describing severe residual symptoms in $11 \%$ of subjects, with $69 \%$ having no or minimal residua. ${ }^{24}$ Also, and importantly, employment change was needed in 38\% of cases and leisure activities had altered in $52 \%$ after the illness. However, over $20 \%$ of patients still noticed improvement 2.5-6.5 years after onset. The same authors in 2005 also published findings relating to the same population, in terms of patients' experience of their functioning after 1 year. ${ }^{25}$ Only $33 \%$ felt subjectively completely cured at 1 year. As patients were also objectively assessed at 1 year, proportions of those with ability to walk at 1 year or with persistent significant disability were utilised.

Although pain was not one our pre-established outcome measures analysed and despite not all patients being treated, we decided to also consider an additional prospective study of pain in GBS given this symptom's potential significant impact on subsequent quality of life. In this study of 156 patients, the majority, but not all, treated with IVIg or IVIg and steroids, $66 \%$, had pain in the acute phase and $38 \%$ had pain at 1 year. ${ }^{26}$ Of note, these included patients with pure motor forms of GBS, where pain is unexpected. Interestingly, pain occurrence correlated with previous diarrhoeal illness and adjunction of steroids to IVIg did not help.

Results for each preselected outcome are summarised in table 1. 
Table 1 Summary of preselected outcomes evaluated from data of prospective analyses of adequately treated Guillain-Barré syndrome (GBS) patients with plasma exchange (PE) or intravenous immunoglobulins (IVIg) and pooled results

\begin{tabular}{|c|c|c|c|c|c|c|c|c|c|c|c|}
\hline Study & Design & $\begin{array}{l}\text { Outcome } 1 \\
\text { (ability to } \\
\text { walk with } \\
\text { aid at } \\
4 \text { weeks) }\end{array}$ & $\begin{array}{l}\text { Outcome } 2 \\
\text { (ability to } \\
\text { walk } \\
\text { unaided at } \\
4 \text { weeks) }\end{array}$ & $\begin{array}{l}\text { Outcome } 3 \\
\text { (need for } \\
\text { ventilatory } \\
\text { support at } \\
4 \text { weeks) }\end{array}$ & $\begin{array}{l}\text { Outcome } 4 \\
\text { (ability to } \\
\text { walk } \\
\text { unaided at } \\
6 \text { months) }\end{array}$ & $\begin{array}{l}\text { Outcome } \\
5 \text { (relapse } \\
\text { at } 1 \text { year) }\end{array}$ & $\begin{array}{l}\text { Outcome } 6 \\
\text { (recovery of } \\
\text { full motor } \\
\text { strength at } \\
1 \text { year) }\end{array}$ & $\begin{array}{l}\text { Outcome } 7 \\
\text { (ability to } \\
\text { walk } \\
\text { unaided at } \\
1 \text { year or } \\
\text { later) }\end{array}$ & $\begin{array}{l}\text { Outcome } 8 \\
\text { (persistence } \\
\text { of severe } \\
\text { motor } \\
\text { sequelae at } \\
1 \text { year or } \\
\text { later) }\end{array}$ & $\begin{array}{l}\text { Outcome } 9 \\
\text { (need to } \\
\text { change } \\
\text { employment } \\
\text { due to GBS) }\end{array}$ & $\begin{array}{l}\text { Outcome10 } \\
\text { (death } \\
\text { within } \\
1 \text { year of } \\
\text { diagnosis) }\end{array}$ \\
\hline $\begin{array}{l}\text { Greenwood } \\
\text { et al, } 1984^{11}\end{array}$ & $\begin{array}{l}\text { Therapeutic } \\
\text { (PE), controlled }\end{array}$ & NA & NA & $2 / 14$ & NA & $1 / 14$ & $4 / 14$ & NA & $1 / 14$ & NA & $2 / 14$ \\
\hline $\begin{array}{l}\text { Osterman } \\
\text { et al, } 1984^{12}\end{array}$ & $\begin{array}{l}\text { Therapeutic } \\
\text { (PE), } \\
\text { controlled }\end{array}$ & $12 / 18$ & $7 / 18$ & $4 / 18$ & NA & $1 / 18$ & $16 / 18$ & NA & $1 / 18$ & NA & $1 / 18$ \\
\hline $\begin{array}{l}\text { The GBS Study } \\
\text { Group, } 1985^{14}\end{array}$ & $\begin{array}{l}\text { Therapeutic } \\
\text { (PE), } \\
\text { controlled }\end{array}$ & NA & NA & $26 / 122$ & $100 / 122$ & $2 / 122$ & NA & NA & $22 / 122$ & NA & $3 / 122$ \\
\hline $\begin{array}{l}\text { French } \\
\text { Cooperative } \\
\text { Group, } 1987^{15}\end{array}$ & $\begin{array}{l}\text { Therapeutic } \\
\text { (PE), } \\
\text { controlled }\end{array}$ & $13 / 109$ & $15 / 109$ & $12 / 109$ & NA & $6 / 109$ & $70 / 109$ & NA & $11 / 109$ & NA & $7 / 109$ \\
\hline $\begin{array}{l}\text { Färkkilä } \\
\text { et al, } 1987^{17}\end{array}$ & $\begin{array}{l}\text { Therapeutic } \\
\text { (PE), } \\
\text { controlled }\end{array}$ & NA & NA & NA & NA & NA & $12 / 13$ & NA & $0 / 13$ & NA & $2 / 13$ \\
\hline $\begin{array}{l}\text { Van der Meché } \\
\text { Schmitz, } 1992^{18}\end{array}$ & $\begin{array}{l}\text { Therapeutic } \\
\text { (PE vs IVIg), } \\
\text { controlled }\end{array}$ & NA & NA & NA & NA & NA & NA & NA & NA & NA & $3 / 150$ \\
\hline $\begin{array}{l}\text { French } \\
\text { Cooperative } \\
\text { Group, } 1997^{19}\end{array}$ & $\begin{array}{l}\text { Therapeutic } \\
\text { (PE), } \\
\text { controlled and } \\
\text { 'dose-ranging' }\end{array}$ & $6 / 45 \neq$ & $13 / 45 \neq$ & $0 / 45^{* *}$ & NA & $14 / 3619$ & 210/361 ब & NA & $41 / 361$ ฯ & NA & $14 / 3619$ \\
\hline $\begin{array}{l}\text { PE/Sandoglobulin } \\
\text { Trial, } 1997^{20}\end{array}$ & $\begin{array}{l}\text { Therapeutic PE } \\
\text { versus IVIg versus } \\
\text { PE+IVIg }\end{array}$ & NA & NA & NA & NA & NA & NA & NA & $57 / 365^{*} \dagger$ & NA & $19 / 379$ \\
\hline $\begin{array}{l}\text { van Koningsveld } \\
\text { et al, } 2004^{21}\end{array}$ & $\begin{array}{l}\text { Therapeutic } \\
\text { IVlg }+ \text { PE } \\
\text { versus IVIg+ } \\
\text { placebo }\end{array}$ & NA & NA & NA & NA & NA & NA & $184 / 225 \S$ & $41 / 225 \dagger †$ & NA & $10 / 225 \S$ \\
\hline $\begin{array}{l}\text { Bernsen } \\
\text { et al, 2002 }\end{array}$ & $\begin{array}{l}\text { Therapeutic } \\
\text { (PE vs IVIg), } \\
\text { controlled }\end{array}$ & NA & NA & NA & NA & NA & NA & $108 / 122$ & $14 / 122$ & $31 / 82$ & NA \\
\hline Total & & $\begin{array}{l}31 / 172 \\
(18 \%)\end{array}$ & $\begin{array}{l}35 / 172 \\
(20.3 \%)\end{array}$ & $\begin{array}{l}44 / 308 \\
(14.3 \%)\end{array}$ & $\begin{array}{l}100 / 122 \\
(82 \%)\end{array}$ & $\begin{array}{l}24 / 624 \\
(3.8 \%)\end{array}$ & $\begin{array}{l}312 / 515 \\
(\mathbf{6 0 . 6} \%)\end{array}$ & $\begin{array}{l}292 / 347 \\
(84.1 \%)\end{array}$ & $\begin{array}{l}188 / 1349 \\
(13.9 \%)\end{array}$ & $\begin{array}{l}31 / 82 \\
(37.8 \%)\end{array}$ & $\begin{array}{l}61 / 1391 \\
(4.4 \%)\end{array}$ \\
\hline \multicolumn{12}{|c|}{$\begin{array}{l}\text { The values in bold correspond to the percentages for each outcome. } \\
\text { *Excluding missing data in each treated group. } \\
\text { †Considering } 48 \text {-week instead of } 52 \text {-week follow-up data. } \\
\text { ¥Only data for these outcomes were available for patients in the 'mild' group (obtained from the Cochrane review). } \\
\text { Slncluding both treated groups which were equivalent and averaging. } \\
\text { IIncluding all patients in the effectively treated groups (ie, } 46 \text { in the two PE in the group for mild disease; the } 155 \text { treated by four PE in the moderate disease group; all } 161 \text { treated patients } \\
\text { by four or six PE in the severe disease group). } \\
\text { ** Included mild group. }\end{array}$} \\
\hline
\end{tabular}

\section{Predictors of prognosis in GBS: descriptive review of the} literature

We here used data from studies where a majority, but not necessarily all patients, had received adequate treatment to evaluate the currently proposed predictors of prognosis in GBS. We separated for ease of reference, clinical, electrophysiological and serological markers, although considerable overlap proved inevitable as several groups of investigators studied different predictors among the three categories. Clinical predictors were for convenience separated between those relating to mechanical ventilation and those relating to long-term disability.

\section{Clinical predictors}

Predictors of mechanical ventilation

Both French PE trials ${ }^{15}{ }^{19}$ first gave rise to a large analysis of the clinical predictors of mechanical ventilation. ${ }^{27}$ Multivariate analysis identified five predictors of mechanical ventilation within 30 days of admission which were: (1) a time from symptom onset to admission of $<7$ days, (2) inability to cough, (3) inability to stand, (4) inability to lift the elbows and (5) inability to lift the head. Having several predictors increased any individual patient's risk of requiring mechanical ventilation.

Walgaard et al more recently published a multivariate logistic regression model for early prediction of respiratory insufficiency in GBS. ${ }^{28}$ Again, data prospectively collected from 397 patients from two previously discussed therapeutic trials and a pilot study. ${ }^{182129}$ Results were validated in a separate cohort of 191 GBS patients followed up prospectively in the setting of a pilot study $^{30}$ and of an observational study. Multivariate logistic regression analysis showed that (1) Medical Research Council (MRC) Sum Score at admission, (2) number of days between onset of weakness and admission and (3) facial and/or bulbar weakness at admission were all strong predictors of mechanical ventilation in the first week of hospital stay. An 'Erasmus GBS Respiratory Insufficiency Score' or 'EGRIS' was derived on the regression coefficients of these three predictors in the combined 
cohort of patients from the derivation and validation sets. The EGRIS provided an estimated risk of mechanical ventilation based on five categories for the MRC Sum Score (MRC Sum Score 60-51: 0; 50-41: 1; 40-31: 2; 30-21: 3; $\leq 20: 4)$, three categories for days between onset of weakness and hospital admission ( $>7$ days: 0 ; $4-7$ days: $1 ; \leq 3$ days: 2 ), and two categories for facial/bulbar weakness at admission (absence: 0; presence: 1). Risk categories for respiratory insufficiency were identified, EGRIS of $0-2$ corresponding to a 'low risk' (4\%), EGRIS 3-4 corresponding to an 'intermediate risk' (24\%) and EGRIS 5-7 labelled as 'high risk' (65\%).

A prospective study of 76 GBS patients from Iran $(80 \%$ treated with PE or IVIg) indicated a significant correlation between a history of diarrhoea and subsequent need for mechanical ventilation. Previous diarrhoea predicted worse outcome at 6 months. ${ }^{31}$

\section{Predictors of long-term functional disability}

Analysis of data from The Plasma Exchange/Sandoglobulin trial participants demonstrated that death or inability to walk at 48 weeks was associated with preceding diarrhoea, severe arm weakness and age $>50$ years. $^{32}$

Visser and coworkers, using data of 147 patients who had participated in the Dutch GBS trial comparing IVIg and PE, ${ }^{18}$ found by multivariate logistic regression analysis that a previous gastrointestinal illness, age $>50$ years and MRC Sum Score $<40$ pretreatment were predictors of a poor outcome. ${ }^{33}$ Subsequently, using data from 388 patients previously included in trials, ${ }^{18} 2129$ van Koningsveld et al derived a clinical prognostic scoring system for GBS outcome at 6 months. ${ }^{34}$ The findings were then validated in 374 other patients who had participated in another international randomised trial. ${ }^{20}$ All data had been prospectively collected. In the multivariate analysis, age, preceding diarrhoea and GBS disability score at 2 weeks after study entry emerged as the three main predictors of poor outcome at 6 months. An 'Erasmus GBS Outcome Score' (EGOS) was derived by the authors, where score ranged from 1 to 7 , with three categories for age (>60 (1 point), 41-60 (0.5 point), $<40$ (0 point)), two categories for diarrhoea (presence (1 point) or absence $(0$ point $)$ ) and five categories for GBS disability score (grade 0 or 1 (1 point), 2 (2 points), 3 (3 points), 4 (4 points) or 5 (5 points)), at 2 weeks. As a result, the authors were able to provide stratification into four groups of roughly equal size using derivation and validation patient samples. An EGOS of 1-3 implied a mean risk of inability to walk independently at 6 months of $0.5 \%$, an EGOS of $3.5-4.5$ implied a mean risk of $7 \%$, an EGOS of five implied a mean risk of $27 \%$ and an EGOS of 5.5-7 implied a mean risk of $52 \%$.

More recently, Walgaard et al also published a clinical prediction model applicable early in the course of GBS predicting outcome at 6 months. ${ }^{35}$ As in their study on respiratory insufficiency described above, the investigators used the same above-mentioned cohorts of patients for derivation and validation. Multiple logistic regression was used and (1) high age, (2) preceding diarrhoea and (3) low MRC Sum Score at admission and day 7 were independently associated with being unable to walk at 4 weeks, 3 months and 6 months. The authors as a result proposed a 'modified EGOS', which they claimed, in contrast to the EGOS, could be used at hospital admission and day 7 , with a greater prognostic accuracy when used at day 7 , when MRC Sum Score proves a more accurate predictor. The main difference with the EGOS was the use of the MRC Sum Score rather than the GBS disability score, as the model using the former performed better.
Electrophysiological predictors

The American Plasma Exchange trial data, ${ }^{14}{ }^{36}$ in univariate analysis, showed as the most powerful predictor of poor outcome a mean distal compound muscle action potential (CMAP) amplitude $<20 \%$ of lower limit of normal. In multivariate analysis, distal CMAP was, together with ventilatory status, the factor influencing the percentage of patients improved at 4 weeks. When time to improve by 1 grade on the GBS disability scale was the outcome measure evaluated, prior length of illness $>7$ days was also a significant predictor. When time to reach GBS disability grade 2 (independent walking) was the analysed outcome, age was additionally a significant predictor. In a further analysis of participants of the Plasma Exchange/Sandoglobulin trial, ${ }^{37}$ neurophysiological findings were classified ad hoc as primary demyelinating, primary axonal, equivocal, inexcitable or normal. An association was found between inexcitable nerves and death or inability to walk unaided at 48 weeks. However, no difference of outcome was detected between axonal and demyelinating forms.

A French analysis studying prospectively 60 consecutive cases (52 treated with PE or IVIg and eight untreated) suggested that demyelinating electrophysiology may be a predictor of mechanical ventilation. ${ }^{38}$ The same group later described, in an analysis of 70 subjects (62 treated with PE or IVIg, eight untreated), a prospective study of phrenic nerve electrophysiology and its relation with need for mechanical ventilation, which they failed to confirm. They concluded that prediction of respiratory failure should rely on clinical features and vital capacity measurements only. ${ }^{39}$ These authors otherwise described in another prospective study of 154 GBS patients (137 treated by PE or IVIg) over an 8-year period (1998-2006) the clinical and electrophysiological predictors of respiratory failure. ${ }^{40}$ Demyelinating electrophysiology was found more common in patients requiring ventilation. Quite puzzling, in our opinion, was that none of the patients who had to be ventilated had axonal electrophysiology whereas a substantial proportion of non-ventilated patients had equivocal electrophysiology. Conduction block affecting the common peroneal nerve was also shown to be a useful predictor of mechanical ventilation. Vital capacity was found useful as additional parameter. Conduction block $<44.4 \%$ taken in combination with a vital capacity $>81 \%$ than predicted indicated $a<2.5 \%$ chance of requiring mechanical ventilation. On the other hand, a similar degree of conduction block, but a vital capacity of $17 \%-80 \%$, implied a chance of mechanical ventilation of about $28 \%$. Interestingly, they found that conduction block $>44.4 \%$ independently suggested a risk of mechanical ventilation of about $40 \%$. Otherwise poor recovery at 6 months, defined as a GBS grade $>2$, was predicted independently by the aforementioned degree of conduction block of the common peroneal nerve and age $>40$ years. Importantly, low distal median CMAP amplitudes were not found to be predictive although summated CMAPs were not analysed or described.

In another recent prospective Iranian study, axonal electrophysiology predicted a worse outcome at 6 months. ${ }^{31}$

Finally, another recent prospective French study described a not better specified 'sciatic nerve motor conduction block' together with a clinical feature described as 'lack of foot flexion ability' at admission to intensive care, and at the end of immunotherapy, as significantly associated with prolonged mechanical ventilation beyond 15 days. ${ }^{41}$ Neither the electrophysiological nor the clinical parameter was further defined or explained by the authors and remained most unclear. 
Biological predictors

Few studies, including limited numbers of patients, addressed the potential use of biological markers as prognostic predictors in GBS. In the Plasma Exchange/Sandoglobulin trial participants, anti-GM1 antibodies were present in a higher proportion of patients with axonal physiology or inexcitable nerves, and patients with pure motor GBS were more likely to have IgG anti-GM1 antibodies and to have had preceding diarrhoea but had a similar outcome to that of other GBS patients. From the same trial, further published results of prognostic factor analysis showed that death or inability to walk at 48 weeks was associated with raised soluble interleukin-2 receptor concentration and, unexpectedly, with absence of IgM anti-GM1 antibodies. ${ }^{32}$ These results contrasted with what had been described by several groups during the previous decade in that patients with GBS and $C$ jejuni infection were more likely to have neurophysiological features of axonal neuropathy, anti-GM1 antibodies, pure motor GBS and a worse outcome than other GBS patients. ${ }^{42-44}$

A study of 41 prospectively recruited GBS patients (32 treated with PE or IVIg) was described in relation to IgG anti-GM1 antibody status. ${ }^{45}$ The anti-GM1 positive group showed two different patterns of recovery and included a significantly higher proportion of patients with poor recovery, but also a significantly higher proportion with markedly rapid recovery. Underlying correlation with $C$ jejuni serology was not ascertained. A further study of the prognostic value of anti-GM1 antibodies evaluated a total of 134 consecutive GBS patients over 6 months. ${ }^{46}$ It found positivity to anti-GM1 antibodies of the IgG1 subclass was the most frequent, was associated with preceding gastro-enteritis and positive $C$ jejuni serology, as well as slow/incomplete recovery. On the other hand, the IgG3 subtype, less frequent, was associated with preceding respiratory illness and rapid recovery within a month. In this study, the outcome could be influenced by various treatments received. The authors, however, concluded that at least in the $21 \mathrm{PE}$ treated patients, IgG subclass of anti-GM1 antibody was closely associated with outcome because the frequency of PE treatment did not differ between the patients with the IgG1 and IgG3 antibodies. ${ }^{46}$ More recently, a prospective, Brazilian study of 41 IVIg treated GBS patients followed up for at least 4 months was unable to detect any impact on worse prognosis of anti-GM1 antibodies and positive $C$ jejuni serology. ${ }^{47}$

Visser et $a l^{\beta 3}$ found in addition to the clinical predictors described earlier that a recent cytomegalovirus infection was an indicator of poor outcome. These findings were consistent with those of a previous study by the same group which had indicated high frequency of respiratory insufficiency, cranial neuropathy and severe sensory loss in cytomegalovirus-associated GBS. ${ }^{48}$

Raised liver enzymes were found to represent a predictor of mechanical ventilation in the participants of the French PE studies, ${ }^{27}$ although this finding has not been replicated since to our knowledge.

A first prospective analysis of 23 GBS patients was described as showing CSF neurofilament level as a biomarker for electrophysiological axonal damage, and of worse motor and functional outcome. ${ }^{49}$ A further larger prospective multicentre controlled study demonstrated the utility of CSF neurofilament and $\tau$, as useful prognostic markers. This study also showed that higher age and need for ventilatory support were associated with poorer prognosis. ${ }^{50}$ In another study including 20 AIDP and 17 axonal GBS patients (28 treated by IVIg, five treated with PE and four untreated), serum levels of glial fibrillar acid protein were increased in axonal subtypes compared with AIDP patients and controls and correlated with GBS functional grade at 6 months. ${ }^{51}$

A prospective French study of the relationship between plasma cortisol and respiratory failure in 93 GBS patients (82 treated by PE or IVIg) ${ }^{52}$ showed after adjustment for validated clinical and electrophysiological predictors increased baseline cortisol level as an independent predictor for respiratory failure at least $24 \mathrm{~h}$ later.

A recent analysis from India prospectively studied 50 GBS patients and described the syndrome of inappropriate secretion of antidiuretic hormone (SIADH) in $48 \%$ of cases at some stage of the illness. ${ }^{53} \mathrm{MRC}$ scores at admission and discharge were higher in patients with SIADH who on the other hand had a higher rate of bulbar weakness and greater need for ventilatory support. Age $>50$ years, ventilatory support, hyponatremia and bulbar weakness were significantly associated with mortality. In this observational study, 23/24 GBS patients with SIADH required $\mathrm{PE}$ compared with only $8 / 26$ without SIADH.

We summarise in figure 1 the findings from the selected literature of predictors of mechanical ventilation and of later functional prognosis in GBS. Table 2 highlights what we believe represent, at this point in time, the main clinically useful prognostic predictors from each category.

\section{DISCUSSION}

We have here reviewed the prospective English-language literature in relation to outcome and its predictors in GBS as currently treated with PE or IVIg. Although clearly desirable, a metaanalysis providing risk ratios for each one of the predictors of poor prognosis was in our opinion unfortunately not feasible reliably or meaningfully due to the large heterogeneity of the various studies analysed in this review.

Even when appropriately treated GBS remains fatal in about $4 \%$ of cases, up to about $20 \%$ of patients are able to walk unaided at 4 weeks, and only $60 \%$ recover full motor strength at 1 year, at which stage about $14 \%$ are left with a severe disability. Importantly, $>80 \%$ are able to walk independently at 6 months. Modest further improvement is usually to be expected, with this figure only reaching $84 \%$ at 1 year. However, individual patients may experience further slow recovery up to 6 years after presentation. These findings highlight the current limitations of available therapies for GBS and the need to find newer, more effective treatment options. The issue of a second dose of IVIg, the usefulness of which was suggested by pharmacokinetic studies $^{54}$ and currently under investigation, ${ }^{55}$ is raised. The relapse rate at 1 year was $3.8 \%$ in agreement with previously reported figures. ${ }^{56} 57$ Neither PE nor IVIg has shown an impact on reducing deaths, and this highlights the importance of supportive care in the management of GBS.

In the longer-term, it appears clear that GBS impairs function as well as social life beyond 1 year, resulting in work changes in nearly $40 \%$ of patients and in persistent pain in about $40 \%$ of all cases, including in pure motor forms, at 1 year and likely beyond. These outcomes, although studied in fewer analyses and in smaller cohorts, are of major importance to patients, their carers and treating general practitioners and/or neurologists. GBS, although of acute onset, appears to subsequently become for many patients a chronic condition, severely impacting on lifestyle over years rather than months, sometimes irreversibly. Encouragingly, improvement appears sustained long after disease onset by mechanisms which are uncertain.

One limitation of our review is that all 10 studies selected were performed in Western countries where AIDP is reported as 


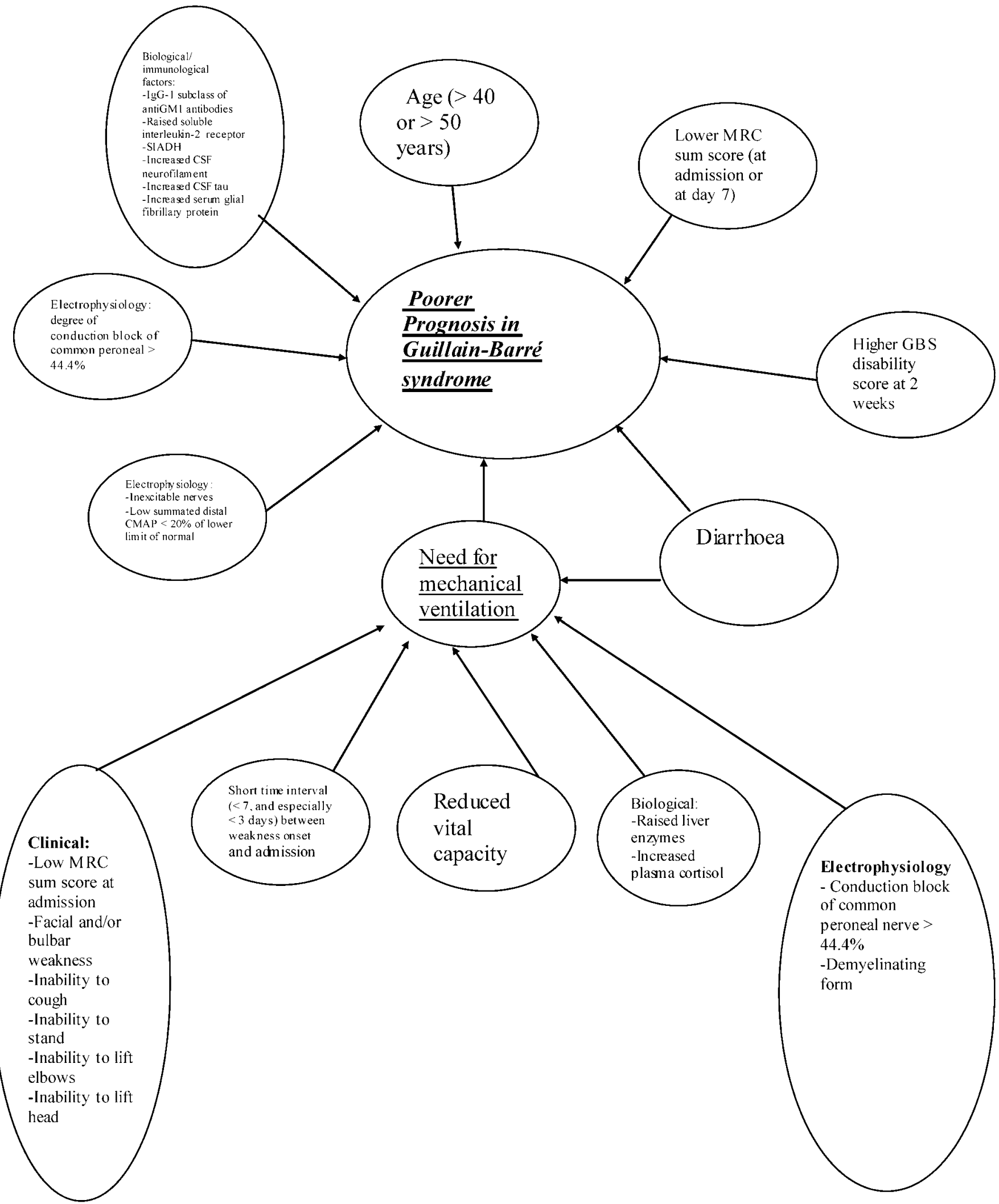

Figure 1 Summary of currently identified/suggested predictors of mechanical ventilation and of prognosis in Guillain-Barré syndrome (GBS). CSF, cerebrospinal fluid; IgG, immunoglobulin G; MRC, Medical Research Council; SIADH, syndrome of inappropriate secretion of antidiuretic hormone.

the most frequent subtype accounting for $90 \%$ of all GBS patients, ${ }^{28}$ whereas the frequency of AMAN is higher in China, Japan and Bangladesh. ${ }^{31} 5859$ It has been debated whether AMAN carries or not a worse prognosis. AMAN patients may either rapidly and fully recover or improve very slowly and incompletely. ${ }^{60}$ This apparent contradiction may be reconciled by the fact that besides axonal degeneration, some AMAN patients with antibodies to gangliosides show transient 
Table 2 Main likely predictors of prognosis in Guillain-Barré syndrome: derived from findings of prospective literature of studies including a majority of treated patients

\begin{tabular}{ll}
\hline Category & Predictor \\
\hline Clinical & Age $>40$ or 50 years \\
& Reduced vital capacity \\
& Need for mechanical ventilation \\
& Preceding diarrhoea \\
& Low MRC Sum Score at admission \\
& Low MRC Sum Score at day 7 postadmission \\
& Short interval between weakness onset \\
& and admission \\
& Facial and/or bulbar weakness \\
& Inexcitable nerves \\
& Low summated distal compound muscle action \\
& potential $<20 \%$ of lower limit of normal \\
Electrophysiological & None of definite value \\
& More confirmatory studies required \\
\hline
\end{tabular}

MRC, Medical Research Council.

conduction block/slowing in intermediate and distal nerve segments which rapidly recovers without the development of abnormal temporal dispersion, a phenomenon named reversible conduction failure. ${ }^{4} 45$ The relative amount of axonal degeneration and reversible conduction failure in an individual patient may well explain the dichotomous outcome pattern in AMAN prognosis. For this reason, the characterisation of primary axonal neuropathy is not necessarily a predictor of poorer outcome. Another drawback of our analysis relates to the fact that except for one study which compared the number of PE needed, ${ }^{19}$ all others studied patients who were unable to walk and therefore initially severely disabled. This undoubtedly impacted on our findings. Our aim was however to evaluate the issue of prognosis in treated adult-onset GBS and exclusion of cases of mild GBS is consequently a limitation that could not be avoided.

Regarding clinical prognostic predictors, most studies demonstrate higher age ( $>40$ or $>50$ years) as an indicator of poor outcome. Similarly, preceding diarrhoea, more severe weakness with consequent low MRC score on admission and high early GBS disability grade all appear reliable predictors of outcome at 6 months, and probably later. Electrophysiologically, the most consistently described finding predictive of poor outcome has been low mean or summated CMAPs. In contrast are the reports of demyelinating electrophysiology and of common peroneal nerve conduction block $>44.4 \%$ as predictors of respiratory failure. ${ }^{39} 45$ It is difficult, from a pathophysiological point of view, to understand why involvement of a leg nerve would be the best indicator of developing respiratory dysfunction. Additionally, electrophysiological assessment was made once only an average of 2 days after admission. A recent study however underlined that it may be difficult or even impossible to make a distinction between axonal and demyelinating features in early recordings. ${ }^{4}$ For these reasons, we believe that more than electrophysiology, clinical factors such as age, facial and bulbar weakness, inability to cough, MRC Sum Score, speed of weakness progression and vital capacity, all easily obtainable at bedside, should be used in priority to predict mechanical ventilation.

Positivity of antibodies to gangliosides can either suggest poor recovery or rapidly reversible weakness. Determination of $\operatorname{IgG}$ subclass, IgG1 or IgG3, may be helpful for prognostic purposes. ${ }^{34}$ It is difficult to explain why, in the study by Hadden et $a l,{ }^{32}$ the presence IgM anti-GM1 antibodies was found to be a good prognostic factor although this might be partly explained by confounding with other factors. CSF neurofilament and serum glial fibrillar acid protein level appear promising potential prognostic markers but results should be confirmed in larger studies.

\section{CONCLUSION}

Knowledge of prognostic factors can substantially improve patient care and provides essential prognostic answers for patients and relatives at an early stage in the course of the illness. There are many persistent uncertainties in the optimal way in which clinical, electrophysiological and biological markers may be combined to establish prognosis at an early stage, and therefore allow, ideally, eventual tailoring of treatment to individual patients' needs. Further larger, prospective international studies of outcome in GBS looking at each one of the relevant measures and potential predictors will hopefully shed more light on these important questions in future. The 'IGOS 1000' (International Guillain-Barré syndrome Outcome Study), ${ }^{61}$ which is to start imminently, will hopefully achieve this important objective.

Contributors Both authors contributed to the literature review, analysis of data, writing of first draft and of the final version submitted.

Competing interests None.

Provenance and peer review Not commissioned; externally peer reviewed.

\section{REFERENCES}

1. McGrogan A, Madle GC, Seaman HE, et al. The epidemiology of Guillain-Barré syndrome worldwide. Neuroepidemiology 2009;32:150-63.

2. Sejvar JJ, Baughman AL, Wise M, et al. Population incidence of Guillain-Barré syndrome: a systematic review and meta-analysis. Neuroepidemiology 2011;36:123-33.

3. van Doorn PA, Ruts $L$, Jacobs BC. Clinical features, pathogenesis, and treatment of Guillain-Barré syndrome. Lancet Neurol 2008;7:939-50.

4. Uncini A, Manzoli C, Notturno F, et al. Pitfalls in electrodiagnosis of Guillain-Barré syndrome subtypes. J Neurol Neurosurg Psychiatry 2010;81:1157-63.

5. Capasso M, Notturno F, Manzoli C, et al. Involvement of sensory fibres in axonal subtypes of Guillain-Barré syndrome. J Neurol Neurosurg Psychiatry 2011;82:664-70

6. Bradley WG. Use of contrast in MR imaging of the lumbar spine. Magn Reson Imaging Clin N Am 1999;7:439-57.

7. Raphaël JC, Chevret S, Hughes RA, et al. Plasma exchange for Guillain-Barré syndrome. Cochrane Database Syst Rev 2002;(4):CD0017898.

8. Hughes RA, Swan AV, van Doorn PA. Intravenous immunoglobulin for Guillain-Barré syndrome. Cochrane Database Syst Rev 2010;(6):CD002063.

9. Eiben RM, Gersony WM. Recognition, prognosis and treatment of the Guillain-Barré syndrome (acute idiopathic polyneuritis). Med Clin North America 1963:47:1371-80.

10. Osuntokun BO, Agbebi K. Prognosis of Guillain-Barré syndrome in the African: the Nigerian experience. J Neurol Neurosurg Psychiatry 1973;36:478-83.

11. Greenwood RJ, Newsom-Davis J, Hughes RAC, et al. Controlled trial of plasma exchange in acute inflammatory polyradiculoneuropathy. Lancet 1984;1:877-9.

12. Osterman P0, Fagius J, Lundemo $\mathrm{G}$, et al. Beneficial effects of plasma exchange in acute inflammatory polyradiculoneuropathy. Lancet 1984;2:1296-9.

13. Mendell JR, Kissel JT, Kennedy MS, et al. Plasma exchange and prednisone in Guillain-Barré syndrome: a controlled randomised trial. Neurology 1985;35:1551-5

14. The Guillain-Barré syndrome study group. Plasmapheresis and acute GuillainBarré syndrome. Neurology 1985;35:1096-104.

15. French Cooperative Group on Plasma Exchange in Guillain-Barré syndrome. Efficiency of plasma exchange in Guillain-Barré syndrome: role of replacement fluids. Ann Neurol 1987:22:753-61.

16. French Cooperative Group on Plasma Exchange in Guillain-Barré syndrome. Plasma exchange in Guillain-Barré syndrome: one year follow-up. Ann Neurol 1992; 32:94-7.

17. Färkkilä $\mathbf{M}$, Kinnunen $\mathbf{E}$, Haapanen $\mathbf{E}$, et al. Guillain-Barré syndrome: quantitative measurement of plasma exchange therapy. Neurology 1987;37:837-40.

18. van der Meché FG, Schmitz PI. A randomized trial comparing intravenous immune globulin and plasma exchange in Guillain-Barré syndrome. Dutch Guillain-Barré Study Group. New Engl J Med 1992;326:1123-9.

19. French Cooperative Group on Plasma Exchange in Guillain-Barré Syndrome. Appropriate number of plasma exchanges in Guillain-Barré Syndrome. Ann Neurol 1997:41:298-306.

20. Plasma Exchange/Sandoglobulin Guillain-Barré Syndrome Trial Group. Randomised trial of plasma exchange, intravenous immunoglobulin, and combined treatments in Guillain-Barré syndrome. Lancet 1997:349:225-30.

21. van Koningsveld R, Schmitz PIM, van der Meché FGA, et al; for the Dutch GBS Study Group. Effect of methylprednisolone when added to standard treatment with intravenous immunoglobulin for Guillain-Barré syndrome: randomised trial. Lancet 2004;363:192-6. 
22. Bernsen RA, Jacobs HM, de Jager AE, et al. Residual health status after GuillainBarré syndrome. J Neurol Neurosurg Psychiatry 1997;62:637-40.

23. Bernsen RA, de Jager AE, Schmitz PI, et al. Residual physical outcome and daily living 3 to 6 years after Guillain-Barré syndrome. Neurology 1999:53:409-10.

24. Bernsen RA, de Jager AE, Schmitz PI, et al. Long-term impact on work and privatelife after Guillain-Barré syndrome. J Neurol Sci 2002;201:13-17.

25. Bernsen RA, de Jager AE, van der Meché FG, et al. How Guillain-Barré patients experience their functioning after one year. Acta Neurol Scand 2005;112:51-6.

26. Ruts L, Drenthen J, Jongen JL, et al. Pain in Guillain-Barré syndrome: a long-term follow-up study. Neurology 2010;75:1439-47.

27. Sharshar T, Chevret S, Bourdain F, et al; For the French cooperative group on plasma exchange in Guillain-Barré syndrome. Early predictors of mechanica ventilation in Guillain-Barré syndrome. Crit Care Med 2003;31:278-83.

28. Walgaard C, Lingsma HF, Ruts L, et al. Prediction of respiratory insufficiency in Guillain-Barré syndrome. Ann Neurol 2010;67:781-7.

29. The Dutch Guillain-Barré Study Group. Treatment of Guillain-Barré syndrome with high-dose immune globulins combined with methylprednisolone: a pilot study. Ann Neurol 1994;35:749-52.

30. Garssen MP, van Koningsveld R, van Doorn PA, et al. Treatment of Guillain-Barré syndrome with mycophenolate mofetil: a pilot study. J Neurol Neurosurg Psychiatry 2007:78:1012-13

31. Arami MA, Yazdchi M, Khandaghi R. Epidemiology and characteristics of GuillainBarré syndrome in the northwest of Iran. Ann Saudi Med 2006:26:22-7.

32. Hadden RDM, Karch H, Hartung HP, et al; The Plasma Exchange/Sandoglobulin Guillain-Barré syndrome Trial Group. Preceding infections, immune factors and outcome in Guillain-Barré syndrome. Neurology 2001:56:758-65.

33. Visser LH, Schmitz PI, Meulstee J, et al. Prognostic factors of Guillain-Barré syndrome after intravenous immunoglobulin or plasma exchange. Dutch Guillain-Barré study group. Neurology 1999;53:598-604.

34. van Koningsveld R, Steyerberg EW, Hughes RA, et al. A clinical prognostic scoring system for Guillain-Barré syndrome. Lancet Neurol 2007:6:589-94.

35. Walgaard C, Lingsma HF, Ruts L, et al. Early recognition of poor prognosis in Guillain-Barré syndrome. Neurology 2011;76:968-75.

36. Cornblath DR, Mellits ED, Griffin JW, et al. Motor conduction studies in GuillainBarré syndrome: description and prognostic value. Ann Neurol 1988;23:354-9.

37. Hadden RDM, Cornblath DR, Hughes RA, et al; The Plasma Exchange/ Sandoglobulin Guillain-Barré syndrome Trial Group. Electrophysiological classification of Guillain-Barré syndrome: clinical associations and outcome. Ann Neurol 1998:44:780-8.

38. Durand MC, Lofaso F, Lefaucheur JP, et al. Electrophysiology to predict mechanical ventilation in Guillain-Barré syndrome. Eur J Neurol 2003;10:39-44.

39. Durand MC, Prigent H, Sivadon-Tardy V, et al. Significance of phrenic nerve electrophysiological abnormalities in Guillain-Barré syndrome. Neurology 2005:65:1646-9.

40. Durand MC, Porcher R, Orlikowski D, et al. Clinical and electrophysiological predictors of respiratory failure in Guillain-Barré syndrome. Lancet Neurol 2006; 5:1021-8.

41. Fourrier $\mathbf{F}$, Robriquet $L$, Hurtevent JF, et al. A simple functional marker to predict the need for prolonged mechanical ventilation in patients with Guillain-Barré syndrome. Crit Care 2011;15:R65.
42. Yuki $\mathrm{N}$, Yoshino $\mathrm{H}$, Sato $\mathrm{S}$, et al. Acute axonal polyneuropathy associated with anti-GM1 antibodies after Campylobacter enteritis. Neurology 1990;40:1900-2.

43. McKhann GM, Cornblath DR, Griffin JW, et al. Acute motor axonal neuropathy: a frequent cause of acute flaccid paralysis in China. Ann Neurol 1993;33:333-42.

44. Rees JH, Soudain SE, Gregson NA, et al. Campylobacter jejuni infection and Guillain Barré syndrome. N Engl J Med 1995;333:1374-9.

45. Kuwabara S, Asahina M, Koga M, et al. Two patterns of clinical recovery in Guillain-Barré syndrome with IgG anti-GM1antibody. Neurology 1998;51:1656-60.

46. Koga M, Yuki N, Hirata K, et al. Anti-GM1 anti antibody lgG subclass. A clinical recovery predictor in Guillain-Barré syndrome. Neurology 2003;60:1514-18.

47. Dourado ME, Duarte RC, Ferreira LC, et al. Anti-ganglioside antibodies and clinical outcome of patients with Guillain-Barré syndrome in North-East Brazil. Acta Neurol Scand 2003;108:102-8.

48. Visser LH, van der Meché FG, Meulstee J, et al. Cytomegalovirus infection and Guillain-Barré syndrome: the clinical, electrophysiologic and prognostic features. Dutch Guillain-Barré study group. Neurology 1996;47:668-73.

49. Petzold A, Hinds N, Murray NM, et al. CSF neurofilament levels: a potential prognostic marker in Guillain-Barré syndrome. Neurology 2006;67:1071-3.

50. Petzold A, Brettschneider J, Jin K, et al. CSF protein biomarkers for proximal axonal damage improve prognostic accuracy in the acute phase of Guillain-Barré syndrome. Muscle Nerve 2009;40:42-9.

51. Notturno F, Caporale CM, De Lauretis A, et al. Glial fibrillary acid protein: a marker of axonal Guillain-Barré syndrome and outcome. Muscle Nerve 2008;38:899-903.

52. Strauss J, Aboab J, Rottmann M, et al. Plasma cortisol levels in Guillain-Barré syndrome. Crit Care Med 2009;37:2436-40.

53. Saifudheen K, Jose J, Abdul Gafoor V, et al. Guillain-Barré syndrome and SIADH. Neurology 2011;76:701-4.

54. Kuitwaard K, de Gelder J, Tio-Gillen AP, et al. Pharmacokinetics of intravenous immunoglobulin and outcome in Guillain-Barré syndrome. Ann Neurol 2009;66:597-603.

55. Walgaard C, Jacobs BC, Cornblath DR, et al: For the Dutch GBS Study Group. Second IVIG dose for Guillain-Barré syndrome with poor prognosis: a double-blind randomized controlled trial. J Peripher Nerv Syst 2011. Meeting of the Peripheral Nerve Society, 25-29 June 2011. Potomac, Maryland. J Peripher Nerv Syst 2011;16:S146.

56. Grand'Maison F, Feasby TE, Hahn AF, et al. Recurrent Guillain-Barré syndrome. Clinical and laboratory features. Brain 1992;115:1093-106.

57. Das A, Kalita J, Misra UK. Recurrent Guillain-Barré syndrome. Electromyogr Clin Neurophysiol 2004:44:95-102.

58. Ogawara K, Kuwabara S, Mori M, et al. Axonal Guillain-Barré syndrome: relation to anti-ganglioside antibodies and Campylobacter jejuni infection in Japan. Ann Neurol 2000;48:624-31

59. Islam Z, Jacobs BC, van Belkum A, et al. Axonal variant of Guillain-Barré syndrome associated with Campylobacter infection in Bangladesh. Neurology 2010;74:581-7.

60. Kuwabara S, Mori M, Ogawara K, et al. Indicators of rapid clinical recovery in Guillain-Barré syndrome. J Neurol Neurosurg Psychiatry 2001;70:560-2.

61. Jacobs BC, Walgaard C, Steyerberg EW, et al; For the Inflammatory Neuropathy Consortium (INC). International Guillain-Barré Syndrome Outcome Study. Sydney, Australia: Peripheral nerve Society Satellite Meeting, 2010. 